\title{
The impact of graft-versus-host disease in the development of oral cancer after allogeneic hematopoietic stem cell transplantation: report of 2 cases
} \author{
Esteves $^{5+}$ and Fabio Abreu Alves ${ }^{2+}$ \\ ${ }^{*}$ Correspondence: graziaju@yahoo.com.br \\ ${ }^{\dagger}$ All authors contributed equally to this work. \\ 'Stomatology Department - Cancer Hospital A.C Camargo, São Paulo, Brazil. \\ ${ }^{2}$ Head and Neck Department- Cancer Hospital A.C Camargo, São Paulo, Brazil. \\ ${ }^{3}$ Pathology Department- Pernambuco Federal University, Recife, Brazil. \\ ${ }^{4}$ Pathology Department- Cancer Hospital A.C Camargo, São Paulo, Brazil. \\ ${ }^{5}$ Pathology Department- Sao Paulo University, São Paulo, Brazil.
}

Graziella Chagas Jaguar ${ }^{1+*}$, Luiz Paulo Kowalski ${ }^{2 \dagger}$, Danyel Elias da Cruz Perez ${ }^{3 \dagger}$, Clovis Antonio Lopes Pinto $^{4 \dagger}$, Carina Magalhães

\begin{abstract}
Background: The development of oral cancer following allogeneic hematopoietic stem cell transplantation (allo-HSCT) is rare and its etiology is controversial. Oral graft-versus-host disease (GVHD) has been described as a possible risk factor for this condition.

Methods and Results: The authors report 2 cases of oral squamous cell carcinoma developed 13 and 15 years after allo-HSCT, respectively. Both patients had no history of smoking or alcohol consumption and the tumor developed in the same area previously affected by oral chronic GVHD. Treatment consisted of surgery and adjuvant radiotherapy in one patient and radiotherapy associated to targettherapy in the other one. The patients are alive and no recurrence was detected after 24 and 22 months of follow-up.

Conclusions: This article showed that oral chronic GVHD following allo-HSCT seem to be a potential risk factor in the development of oral carcinoma and emphasized the importance of long term follow-up periods for hematological transplanted patients.
\end{abstract}

Keywords: Allogeneic hematopoietic stem cell transplantation (allo-HSCT), graft-versus-host disease (GVHD), secondary cancer, oral squamous cell carcinoma

\section{Introduction}

Allogeneic hematopoietic stem cell transplantation (allo-HSCT) is the standard treatment of various hematologic malignancies, as well as hematologic and metabolic disorders, with successful results in survival rates $[\mathbf{1 , 2}]$. This procedure, however, is frequently associated with a wide range of complications, being graft-versus-host disease (GVHD) one of the most important and disabling effect with important impact in patients' quality of life [3].

Previous studies suggest that GVHD may increase the risk for the developing of secondary solid neoplasms, particularly squamous cell carcinoma $[\mathbf{2}, \mathbf{4}, \mathbf{5}]$. This correlation is controversial in the literature. Some authors state that the occurrence of new secondary malignancies may be attributed to several factors such as cumulative toxicity of previous chemotherapy or radiotherapy, conditioning regimes, immunosuppressive GVHD prophylaxis, viral infections, antigenic differences between recipient and donor, gender and age $[6,7,8,9,10]$. On the other hand, the incidence of solid tumors, especially oral squamous cell carcinoma, seems to be higher in patients who developed previous oral GVHD at the same anatomic area $[3,4,5]$.

The exact etiology for this process is still obscure [3]. It has been suggested that the long-term immunologic injury of the mucosa by chronic GVHD inflammatory process may predispose this tissue to malignant transformation $[7,8]$. The aim of this report was to describe the clinical presentation of two patients who developed oral squamous cell carcinoma 13 and 15 years post allo-HSCT, respectively, in the same area previously affected by oral GVHD.

\section{Case 1}

A 50-year-old woman was referred to the Stomatology Department, Hospital AC Camargo, São Paulo, Brazil, for evaluation of symptomatic lesion involving inferior lip with 1 month duration. The patient denied tobacco and alcohol consuption. On history, the patient revealed allo-HSCT 13 years ago due to multiple myeloma. The conditioning regimen transplant included Busulphan ( $1 \mathrm{mg} \backslash \mathrm{Kg} \backslash$ dose for 4 days), cyclophosphamide (45 $\mathrm{mg} \backslash \mathrm{Kg} \backslash$ dose for 2 days) and Melphalan (100mg $\backslash \mathrm{m} 2$ for 1 day). Prophylaxis against GVHD consisted of cyclosporine $A(1,5 \mathrm{mg} \backslash \mathrm{Kg} \backslash$ dose $)$ and methotrexate $(29 \mathrm{mg} \backslash$ Kgldose for 4 days: $D+1, D+3, D+6$ and $D+11)$. According to the hospital records, at day 176 after allo-HSCT, the patient developed bilateral white lichenoid-type lesions on the buccal mucosa and inferior lip (Figure 1). Clinical and histopathological features confirmed oral chronic GVHD. At that time, no topical therapy was carried out.

During our present clinical evaluation, it was noted an

(C) 2013 Jaguar et al; licensee Herbert Publications Ltd. This is an Open Access article distributed under the terms of Creative Commons Attribution License (http://creativecommons.org/licenses/by/3.0). This permits unrestricted use, distribution, and reproduction in any medium, provided the original work is properly cited. 


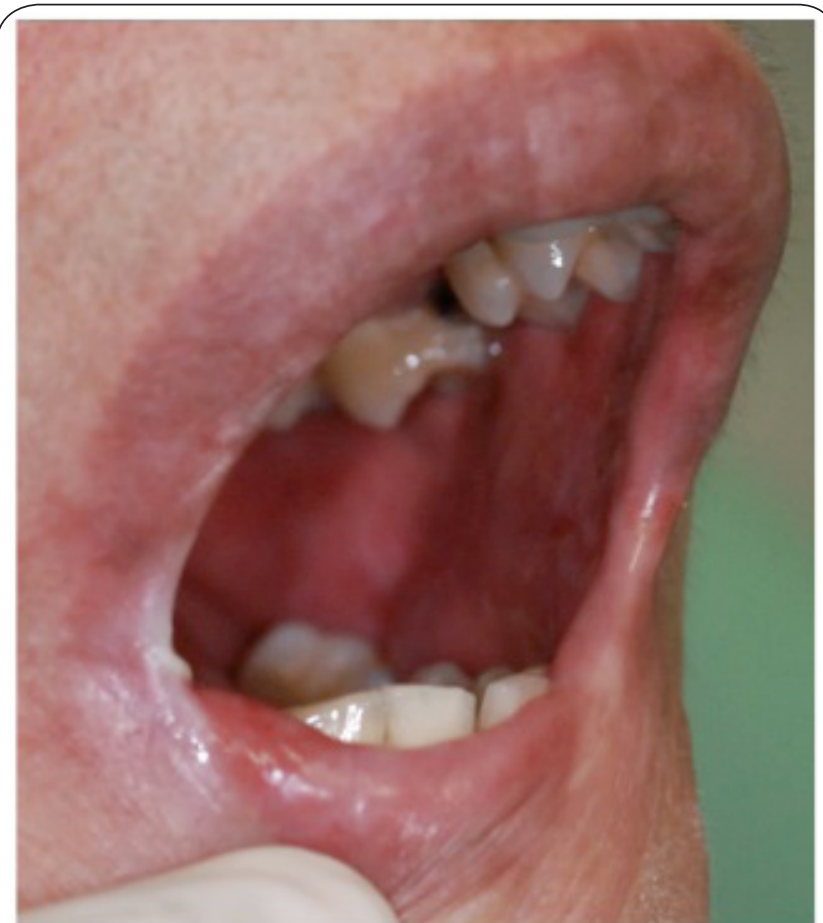

Figure 1. Clinical presentation of the white lichenoidtype lesions on the buccal oral mucosa and inferior lip at day 176 after allo-HSCT.

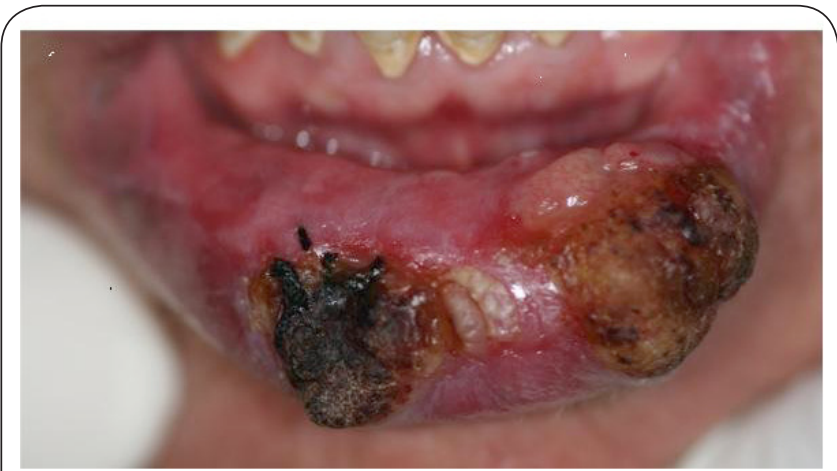

Figure 2. Clinical presentation of squamous cell carcinoma involving the inferior lip developed 13 years after allo-HSCT. It is evident that the tumor occured at the same anatomic area previously affected by oral GVHD.

extensive ulcer with necrotic surface and indurate borders involving inferior lip (Figure 2). The main diagnosis hypothesis was squamous cell carcinoma. The incisional biopsy confirmed oral squamous cell carcinoma and the tumor was staged as T3N1MO. Treatment consisted of surgery and adjuvant radiotherapy. Patient has no evidence of disease after two years of follow-up.

\section{Case 2}

A 24 year-old woman was referred due to a symptomatic

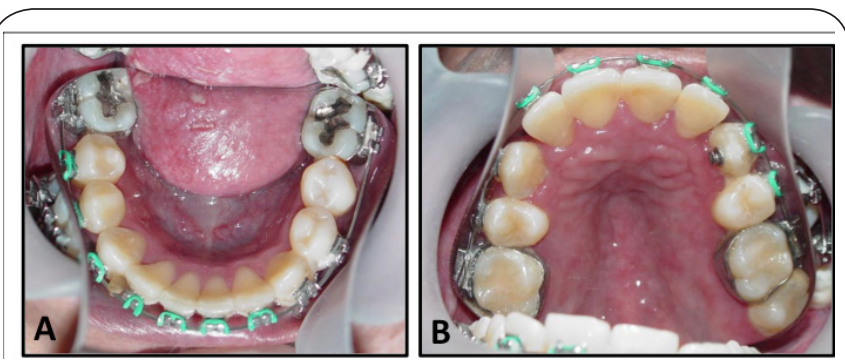

Figure 3 (A-B). Multiple red and white lichenoid erosive lesions affecting tongue (A) and hard palate (B). These lesions were detected at day 158 after allo-HSCT.

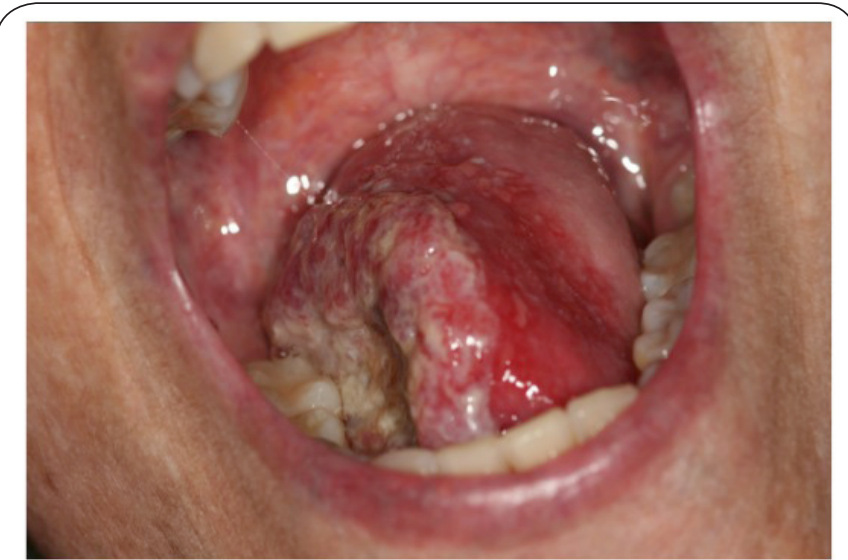

Figure 4. Clinical presentation of squamous cell carcinoma involving entire right border of the tongue extending to the oropharynx developed 15 years after allo-HSCT, showing that the tumor occured at the same anatomic area previously affected by oral GVHD.

lesion in the tongue with 8 months of duration. Patient denied tobacco and alcohol consumption. General medical history revealed an allo-HSCT 15 years ago for acute leukaemia treatment. Conditioning regimen transplant include Busulphan (1 $\mathrm{mg} \backslash \mathrm{Kg} \backslash$ dose for 4 days: D-7, D-6, D-5 and D-4) and cyclophosphamide (120 mg Kg \dose for 2 days: D-3 and D-2). GVHD prophylaxis consisted of methotrexate (19mg $\backslash \mathrm{Kg} \backslash$ dose for 3 days). At day 158 after allo-HSCT, the patient presented multiple red and white lichenoid erosive lesions affecting tongue, hard palate and inferior lip mucosa (Figure 3A-B). Both clinical and histopathological features confirmed oral chronic GVHD. Patient was treated with methotrexate during 6 months.

On clinical evaluation, the patient had a painless indurated mass with necrotic surface measured about $6 \mathrm{~cm}$ involving entire right border of the oral tongue extending to the oropharynx (Figure 4). Again, squamous cell carcinoma was the clinical diagnoses and it was confirmed by incisional biopsy. The clinical stage was T4NOM0. Tumor resection was not indicated due to patient's unfavorable clinical conditions. Consequently, radiotherapy and chemotherapy (cetuximab) 
was indicated. After 22 months of treatment, no recurrence was detected.

\section{Discussion}

The development of secondary malignancies has been considered the major cause of morbidity after allo-HSCT with significant impact on late mortality [10]. The most common secondary malignancies include hematological disease such as leukaemia, Hodgkin's disease, non-Hodgkin's lymphoma and granulocytic sarcoma, which frequently occur in the early period post transplant $[1,8]$. Although rare, secondary solid tumors, especially squamous cell carcinoma in the skin and in the oral cavity, have been reported in the literature $[4,5,11-13]$.

Different to secondary hematological malignancies, the incidence of solid tumor increases with time: $0.4 \%$ in the first 5 years post-transplant, $3.5 \%$ in 10 years and $12.8 \%$ in 15 years [8]. In addition, it is reported that the risk reaches its peak between 8 and 9 years after allo-HSCT, in patients who are 10-29 years old at the time of transplantation while it decreases in those who are older than 30 years [1]. The present cases differ from these studies reported in the literature. Our two patients developed oral squamous cell carcinomas approximately 13 and 15 years after allo-HSCT, respectively. In addition, one patient (case 1) was older than 30 years at the time of transplantation.

The occurrence of oral carcinoma after allo-HSCT has been attributed to several risk factors. Known risk factors for the general population, such as smoking, alcohol consumption and older age are not relevant in these patients $[3,11]$. Oral GVHD, a chronic mucosal inflammation, has been suspected to be a potential risk factor for the development of squamous cell cancers of the oral cavity $[2-5,11,13-14]$. Both of our patients had no history of smoking or alcohol consumption and oral squamous cell carcinoma developed in the same area previously affected by oral GVHD.

GvHD is a frequent complication after allo-HSCT caused by a immunologic reaction from grafting immunocompetent cells to an immunodeficient host [15]. Chronic GVHD occurs in approximately $60-80 \%$ of long-term patients [16] and most often affects the skin, liver, gastrointestinal tract, lungs and eyes $[11,15]$. Oral GVHD occurs in approximately $60-80 \%$ of patients with clinical manifestations of atrophy, erythema, lichenoid lesions, xerostomia and oral pain with important impact on eating, drinking and oral hygiene procedures [15]. Clinically, in our patients the carcinoma arose in the oral mucosa that previously had shown hyperkeratotic striae, atrophy, ulceration and pain with clinical and histological diagnosis of oral GVHD. These observations may suggest that chronic GVHD is a strong risk factor for the development of oral squamous cell carcinoma.

The exact mechanism for the malignant transformation of oral GVHD is still unknown. Some authors believe that oral GvHD is histologically identical to oral lichen planus, which it is considered a significant malignant potential lesion [3,5]. In addition, both diseases have the same pathogenesis involving T-lymphocytes that chronically attack the oral epithelium. In agreement to the literature, in our opinion, one of the main aspects to malignant transformation is the long-term immunologic damage to the mucosa by T-cells.

The time between the diagnosis of oral GVHD and carcinoma ranged from 2 to more than 10 years [14]. The presence of dysplastic alterations in the oral mucosa before carcinoma onset is not reported in the literature. In the present series, carcinoma was diagnosed 13 (patient 1 ) and 15 years (patient 2) after oral GVHD diagnosis and no dysplastic alterations were presented in GVHD lesions. Further studies focusing on identifying early clinical and pathological alterations aiming to early diagnose of cancer could significantly improve survival related patient's quality of life.

\section{Conclusion}

This article showed that oral GVHD following allo-HSCT seem to be a potential risk factor in the development of oral carcinoma even a very long time after transplant. Due to that, we emphasized the importance of long follow-up periods for these patients and to biopsy any suspicious lesions.

\section{Competing interests}

The authors declare that they have no competing interests.

Publication history

Received: 18-Feb-2013 Revised: 30-Apr-2013

Accepted: 16-May-2013 Published: 04-Jun-2013

\section{References}

1. Curtis RE, Rowlings PA, Deeg HJ, Shriner DA, Socie G, Travis LB, Horowitz MM, Witherspoon RP, Hoover RN, Sobocinski KA, Fraumeni JF, Jr. and Boice JD, Jr.: Solid cancers after bone marrow transplantation. N EnglJ Med 1997, 336:897-904. | Article | PubMed

2. Abdelsayed RA, Sumner T, Allen CM, Treadway A, Ness GM and Penza SL: Oral precancerous and malignant lesions associated with graft-versushost disease: report of 2 cases. Oral Surg Oral Med Oral Pathol Oral Radiol Endod 2002, 93:75-80. | Article | PubMed

3. Demarosi F, Soligo D, Lodi G, Moneghini L, Sardella A and Carrassi A: Squamous cell carcinoma of the oral cavity associated with graft versus host disease: report of a case and review of the literature. Oral Surg Oral Med Oral Pathol Oral Radiol Endod 2005, 100:63-9. | Article | PubMed

4. Millen FJ, Rainey MG, Hows JM, Burton PA, Irvine GH and Swirsky D: Oral squamous cell carcinoma after allogeneic bone marrow transplantation for Fanconi anaemia. Br J Haematol 1997, 99:410-4. | Article | PubMed

5. Zhang L, Epstein JB, Poh CF, Berean K, Lam WL, Zhang X and Rosin MP: Comparison of HPV infection, p53 mutation and allelic losses in posttransplant and non-posttransplant oral squamous cell carcinomas. $J$ Oral Pathol Med 2002, 31:134-41. | Article | PubMed

6. Socie G, Henry-Amar M, Bacigalupo A, Hows J, Tichelli A, Ljungman P, McCann SR, Frickhofen N, Van't Veer-Korthof E and Gluckman E: Malignant tumors occurring after treatment of aplastic anemia. European Bone Marrow Transplantation-Severe Aplastic Anaemia Working Party. N Engl J Med 1993, 329:1152-7. | Article | PubMed

7. Otsubo H, Yokoe H, Miya T, Atsuta F, Miura N, Tanzawa H and Sato K: Gingival squamous cell carcinoma in a patient with chronic graftversus-host disease. Oral Surg Oral Med Oral Pathol Oral Radiol Endod 1997, 84:171-4. | Article | PubMed 
Jaguar et al. Hematology and Leukemia 2013,

8. Kolb HJ, Socie G, Duell T, Van Lint MT, Tichelli A, Apperley JF, Nekolla $E$, Ljungman $P$, Jacobsen $N$, van Weel $M$, Wick $R$, Weiss $M$ and Prentice HG: Malignant neoplasms in long-term survivors of bone marrow transplantation. Late Effects Working Party of the European Cooperative Group for Blood and Marrow Transplantation and the European Late Effect Project Group. Ann Intern Med 1999, 131:738-44. | Article | PubMed

9. Miller CS and Johnstone BM: Human papillomavirus as a risk factor for oral squamous cell carcinoma: a meta-analysis, 1982-1997. Oral Surg Oral Med Oral Pathol Oral Radiol Endod 2001, 91:622-35. | Article | PubMed

10. Bhatia S, Ramsay NK, Steinbuch M, Dusenbery KE, Shapiro RS, Weisdorf DJ, Robison LL, Miller JS and Neglia JP: Malignant neoplasms following bone marrow transplantation. Blood 1996, 87:3633-9. | Article | PubMed

11. Montebugnoli L, Gissi DB, Marchetti C and Foschini MP: Multiple squamous cell carcinomas of the oral cavity in a young patient with graft-versus-host disease following allogenic bone marrow transplantation. Int J Oral Maxillofac Surg 2011, 40:556-8. | Article | PubMed

12. Yokota A, Ozawa S, Masanori T, Akiyama H, Ohshima K, Kanda Y, Takahashi S, Mori T, Nakaseko C, Onoda M, Kishi K, Doki N, Aotsuka N, Kanamori $\mathrm{H}$, Maruta A, Sakamaki $\mathrm{H}$ and Okamoto S: Secondary solid tumors after allogeneic hematopoietic SCT in Japan. Bone Marrow Transplant 2012, 47:95-100. | Article | PubMed

13. Myoken $Y$, Sugata T and Iwato K: Squamous cell carcinoma of the oral cavity associated with graft-versus-host disease. Int J Oral Maxillofac Surg 2012, 41:544-5. | Article | PubMed

14. Noguchi K, Nakase M, Inui M, Nakamura S, Okumura $K$ and Tagawa T: A case of tongue carcinoma associated with chronic graft-versus-host disease after allogeneic haematopoietic stem cell transplantation. Aust Dent J 2010, 55:200-2. | Article | PubMed

15. Eggleston $\mathrm{TI}$, Ziccardi VB and Lumerman H: Graft-versus-host disease. Case report and discussion. Oral Surg Oral Med Oral Pathol Oral Radiol Endod 1998, 86:692-6. | Article | PubMed

16. Ratanatharathorn V, Ayash L, Lazarus HM, Fu J and Uberti JP: Chronic graft-versus-host disease: clinical manifestation and therapy. Bone Marrow Transplant 2001, 28:121-9. | Article | PubMed

Citation:

Jaguar GC, Kowalski LP, Perez DEdC, Pinto CAL, Esteves CM and Alves FA: The impact of graft-versus-host disease in the development of oral cancer after allogeneic hematopoietic stem cell transplantation: report of 2 cases. Hematology and Leukemia 2013, 1:4. http://dx.doi.org/10.7243/2052-434X-1-4 